\title{
REVIEW
}

Open Access

\section{The effects of step-count monitoring interventions on physical activity: systematic review and meta-analysis of community- based randomised controlled trials in adults}

Umar A. R. Chaudhry * D, Charlotte Wahlich, Rebecca Fortescue, Derek G. Cook, Rachel Knightly and Tess Harris

\begin{abstract}
Background: Step-count monitors (pedometers, body-worn trackers and smartphone applications) can increase walking, helping to tackle physical inactivity. We aimed to assess the effect of step-count monitors on physical activity (PA) in randomised controlled trials (RCTs) amongst community-dwelling adults; including longer-term effects, differences between step-count monitors, and between intervention components.
\end{abstract}

Methods: Systematic literature searches in seven databases identified RCTs in healthy adults, or those at risk of disease, published between January 2000-April 2020. Two reviewers independently selected studies, extracted data and assessed risk of bias. Outcome was mean differences (MD) with 95\% confidence intervals (Cl) in steps at follow-up between treatment and control groups. Our preferred outcome measure was from studies with follow-up steps adjusted for baseline steps (change studies); but we also included studies reporting follow-up differences only (end-point studies). Multivariate-meta-analysis used random-effect estimates at different time-points for change studies only. Meta-regression compared effects of different step-count monitors and intervention components amongst all studies at $\leq 4$ months.

Results: Of 12,491 records identified, 70 RCTs (at generally low risk of bias) were included, with 57 trials (16,355 participants) included in meta-analyses: 32 provided change from baseline data; 25 provided end-point only. Multivariate meta-analysis of the 32 change studies demonstrated step-counts favoured intervention groups: MD of 1126 steps/day 95\% $[787,1466]$ at $\leq 4$ months, 1050 steps/day [602, 1498] at 6 months, 464 steps/day [301, 626] at 1 year, 121 steps/day [-64, 306] at 2 years and 434 steps/day $[191,676]$ at 3-4 years. Meta-regression of the 57 trials at $\leq 4$ months demonstrated in mutually-adjusted analyses that: end-point were similar to change studies (+ 257 steps/day $[-417,931]) ;$ body-worn trackers/smartphone applications were less effective than pedometers (- 834 steps/day [-1542, -126$]$ ); and interventions providing additional counselling/incentives were not better than those without (- 812 steps/day [-1503, - 122]).

Conclusions: Step-count monitoring leads to short and long-term step-count increases, with no evidence that either bodyworn trackers/smartphone applications, or additional counselling/incentives offer further benefit over simpler pedometerbased interventions. Simple step-count monitoring interventions should be prioritised to address the public health physical inactivity challenge.

(Continued on next page)

\footnotetext{
* Correspondence: uchaudhr@sgul.ac.uk

Population Health Research Institute, St George's, University of London,

Cranmer Terrace, London SW17 ORE, UK
} 
(Continued from previous page)

Systematic review registration: PROSPERO number CRD42017075810.

Keywords: Physical activity, Step-count monitoring, Pedometers, Smartphone applications, Fitness devices, Systematic review, Meta-analysis

\section{Introduction}

Physical activity (PA) reduces all-cause mortality, and delivers important prevention and treatment benefits for many different physical and psychological conditions [1]. The World Health Organisation recognises physical inactivity as an important global health challenge, with more than a quarter of the world's population not meeting current PA recommendations for health [1].

PA interventions can help tackle this global burden, with those employing behaviour change techniques being more effective [2]. Walking is the commonest PA and is an ideal behaviour for interventions to target as: both intensity and frequency can be gradually increased; it provides dynamic aerobic activity with minimal adverse effects [3]; and it can be a good way to achieve the PA guidance of $150 \mathrm{~min}$ of weekly moderate-to-vigorous PA $[1,4]$. Different health drives to promote PA using walking, include campaigns to promote 10,000 steps per day [5], or adding in 3000 steps in $30 \mathrm{~min}$ to usual PA [6], with a recognition that for most people walking at a moderate intensity approximates to 1000 steps in $10 \mathrm{~min}$ [6].

Pedometers use body-worn motion sensors to objectively measure step-counts and are a simple, inexpensive intervention to increase PA levels [5]. Other monitors have gained popularity recently, due to technological advances and their ability to capture more data. These include accelerometers, measuring acceleration forces, incorporated into newer fitness technologies, such as body-tracking devices and smartphone applications, also providing objective PA measures, including step-counts [7]. Earlier systematic reviews and meta-analyses, focussing on pedometers, have highlighted significant increases in PA associated with their use $[8,9]$. However, since these reviews, a number of larger randomized controlled trials (RCTs) with longer follow-up have been published [10-12]. Moreover, many trials incorporated within the earlier reviews included subjective self-report questionnaire outcomes, prone to particular biases [13] and with considerable over-reporting of PA compared to objective PA measures [14]. Finally, the effectiveness of newer fitness technologies, including body-worn tracking devices and smartphone applications in increasing PA levels needs to be explored systematically.

Thus, the main aim of this review was to examine the effects of step-count monitoring devices (pedometers, body-worn trackers and smartphone applications) on objectively measured step-counts among the adult general population.

Specific objectives were:

- To determine whether intervention effects varied with length of follow-up;

- To determine whether certain types of intervention were more effective than others (for example, studies reporting change in PA from baseline compared to end-point only, pedometers compared to other step-count monitors, and interventions providing additional counselling/incentives compared to those not).

\section{Methods}

Our systematic review was performed and reported in accordance with the 2009 PRISMA statement [15].

\section{Search strategy}

We searched for articles indexed in Ovid Medline, EMBASE, PsycINFO, Web of Science, Cochrane Library, CINAHL and ASSIA that were published from January 2000 using a combination of controlled vocabulary (for example, Medical Subject Headings (MeSH)) and keyword searching. RCTs published after the year 2000 were selected due to the emerging technology of measuring step-counts amongst the general population from this time onwards. The initial search was conducted in September 2017, with a forward citation search of included studies conducted in June 2018, and an updated search carried out in April 2020, to incorporate the most recent evidence and to ensure longer follow-up periods were included. Further studies were selected after examining the references of included studies and from earlier systematic review. Search strategies are provided for MEDLINE [Additional file 1] and other databases [Additional file 2].

\section{Study selection, inclusion and exclusion criteria}

Study inclusion and exclusion criteria were developed in accordance with the PICOS framework $[15,16]$ and are fully described in Additional file 3. We included RCTs involving adults, published in English-language. Cluster randomised trials were eligible, as were cross-over studies, providing data were available at the end of the first phase to avoid possible intervention carry-over effects. 
Studies of healthy adults, those at risk of disease, or those with pre-existing chronic medical conditions (either physical or psychological) as expected within a general population were included. Studies were excluded if participants were hospital or institution-based, selected on the basis of a health condition; or involved highperformance training. Community-based programmes including step-count monitoring interventions (pedometers, other body-worn fitness devices and smartphone applications) and providing objectively measured stepcount outcomes, either with change in step-count from baseline (change-on-change) or with only step-counts at follow-up (end-point only) were included. The intervention could feature any form of pedometer or any other device, either physical or electronic, which measured the user's step-count, including mobile phone applications and common body-worn fitness devices. Outcomes reported at all time-points following intervention completion were included. Where studies had more than one step-count monitoring intervention, all were selected. Comparators included control group participants predominantly receiving 'usual standard care' or healthcare advice with minimal active engagement (that is, not using a step-count monitoring device). Where there was more than one control group, the one with least active engagement was selected. This review focussed on RCTs as these are considered the gold-standard for assessing interventions; randomisation, when correctly implemented, eliminates bias in treatment assignment and limits confounding. The search was restricted to English-language studies due to the lack of funding, as specified in our protocol.

References were initially managed using EndNote X7.7.1 [17], where duplicates were removed. We applied an RCT classifier [18] and studies deemed to have $\mathrm{a} \leq$ $5 \%$ chance of being an RCT were excluded, after validation on a $5 \%$ sample. The RCT classifier works by utilising a machine learning algorithm to accurately identify randomised controlled trials [18]. This was possible for the initial search conducted in September 2017, but was not available for the later updated search conducted in April 2020. Two review authors then independently screened the remaining titles and abstracts using an inclusion check-list [Additional file 4] and Rayyan (a web application to rapidly screen a large number of records for selection) [19]. Full-texts of potentially eligible studies were obtained and assessed by two authors independently, with discrepancies resolved through discussion and consultation with the wider author team (RF / TH / DC).

\section{Data extraction}

Data on characteristics of included studies were independently extracted by two reviewers (UC and RK) using a pre-piloted data extraction sheet. Data included: 1) study design, total participants, participant demographic details, follow-up length; 2) intervention details; 3) outcome measures. Where further clarification was required regarding data, study authors were contacted to provide this information. The collected data for the 32 studies which provided mean between-group difference in change from baseline step-count (change-on-change) and the 25 studies which provided end-point only stepcounts are provided in Additional file 5.

\section{Risk of bias assessment}

The risk of bias was assessed independently for each study by two reviewers independently, using the Cochrane Risk of Bias tool [16]. Disagreements were resolved through discussion with a third author (RF). A sensitivity analysis based on the Risk of Bias score was not performed, as this was not pre-specified in the protocol.

\section{Differences from published protocol}

Compared to the outlined protocol, one of the secondary objectives focusing on different sub-groups based on demographics was not undertaken due to the lack of sufficient data in many studies. Nor did we analyse data on moderate-to-vigorous physical activity (MVPA) as a secondary outcome; this was problematic due to the heterogenous reporting of MVPA outcomes and was unnecessary because of the ubiquitous availability of stepcount data.

\section{Data analysis}

The primary outcome was step-count, reported with 95\% confidence intervals $(\mathrm{CI})$. We preferred change in step count from baseline as we anticipated within-person scores to be correlated and that change would result in greater precision and be less prone to bias, since individuals are used as their own controls, than studies based on measurements at follow-up only. If both change from baseline and end-point scores were available, we extracted both. If available, we preferentially used analysis of covariance (ANCOVA) measures of change in our metaanalyses. For trials with multiple relevant intervention arms, we performed adjustments to the data before performing the meta-analysis, by splitting the comparator group to avoid double-counting. The $\mathrm{I}^{2}$ statistic was used to measure the heterogeneity [20].

Initial meta-analyses were performed and Forest plots created using RevMan 5.3 [21]. As we expected to find between-study heterogeneity, random-effects models were used for the meta-analysis. Potential publication bias was assessed using funnel plots, with sub-setting of the estimates by time of follow-up from randomisation. 
We performed sub-group analyses for different followup periods and meta-regression (described in more detail below) to explore: 1) study outcome type (that is, change-on-change versus end-point studies); 2) type of monitor (that is, pedometer-based interventions versus other step-count monitoring interventions such as bodyworn trackers and smartphone applications); and 3) intensity of intervention (that is, comparing interventions additionally offering individual / group counselling or financial incentives, with those that did not). We were unable to explore effect modification by demographic variables or to compare interventions with different contact lengths/ intensities due to the diversity and lack of reporting of these variables.

Additional meta-analyses were carried out using the Stata procedure Mvmeta [22, 23]. Specifically: (i) analysis of estimates changing over time was assessed using multivariate meta-analysis which formally allowed for the same studies appearing at different time points - the outcome was a matrix of 5 variables, with each column corresponding to one of the 5 time points and each row corresponding to a study. Studies contributed data at variable numbers of time points; a-priori we decided that this analysis should be restricted to studies providing change-on-change estimates as the correlation between different time points would differ in end-point only studies; (ii) multi-variable meta-regression was carried out at the first time point ( $\leq 4$ months) to assess whether estimates of effect varied, as described above, by: study outcome type; type of monitor used; and intervention intensity. Details of the Mvmeta options used are given in Additional file 6.

Our review protocol was registered with PROPERO on the 31st August 2017 (registration number: CRD42017075810).

\section{Results}

\section{Study selection}

The PRISMA flow diagram for study selection can be seen in Fig. 1. 25,922 studies were initially identified using database searching in September 2017, forward citation search in June 2018, updated search in April 2020 and from previous systematic reviews, of which 14,423 records remained after removal of duplicates. After application of an RCT classifier 12,491 studies remained eligible for title/abstract screening, of which 498 full-texts were subsequently reviewed. 70 studies met the inclusion for the systematic review.

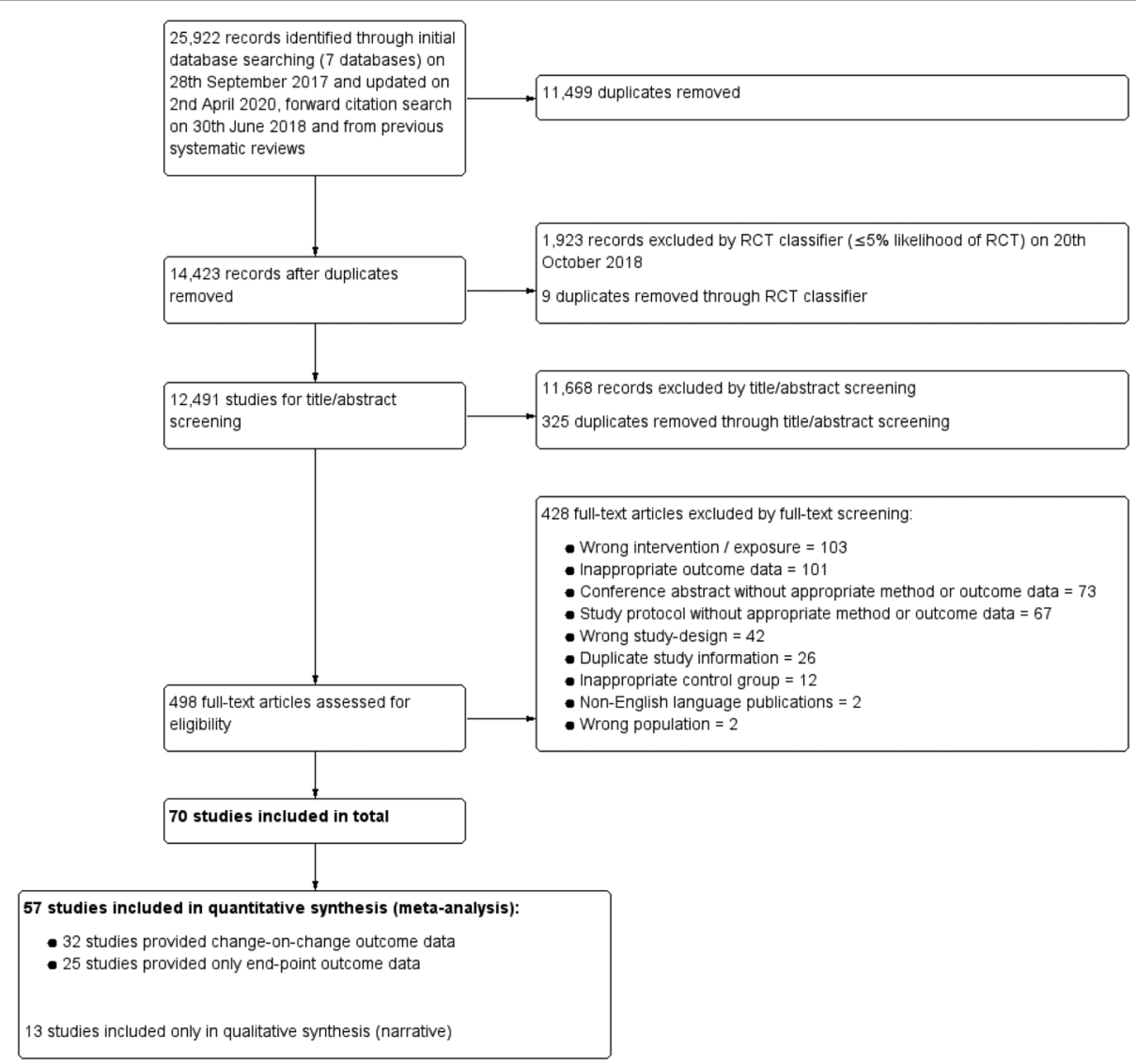

Fig. 1 PRISMA Flowchart Screening of Literature Search and Eligibility 


\section{A) Change-on-Change Outcome Studies}

\begin{tabular}{|c|c|c|c|c|c|c|}
\hline & 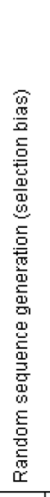 & 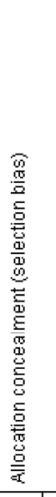 & 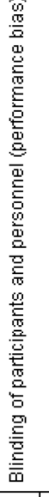 & 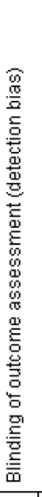 & 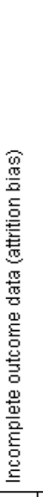 & 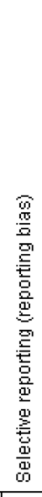 \\
\hline Aguiar 2016 & $\odot$ & - & - & ๑) & • & + \\
\hline Ashton 2017 & $\odot$ & ๑ & - & ๑ & $\rightarrow$ & $\odot$ \\
\hline Baker 2008 & $?$ & ๑) & - & ๑) & • & $?$ \\
\hline Biddle 2015 & $?$ & ? & అ & ๑) & ๑ & 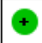 \\
\hline Brackenridge 2016 & $\odot$ & - & - & ๑) & - & 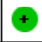 \\
\hline Davies 2016 & 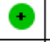 & $?$ & - & ๑) & $?$ & 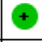 \\
\hline Finkelstein 2016 & 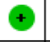 & ๑) & - & ๑) & • & + \\
\hline Garcia-Ortiz 2018 & $\odot$ & $?$ & - & ๑ & $\oplus$ & $?$ \\
\hline Gill 2019 & (†) & () & 은 & 인 & ㄷ & 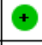 \\
\hline Glynn 2014 & $\oplus$ & ๑) & • & ๑) & ( & $\oplus$ \\
\hline Grey 2019 & $\odot$ & ๑) & - & ๑) & ๑ & 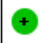 \\
\hline Harris 2015 & ๑ & ๑ & అ & ๑ & 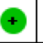 & $\odot$ \\
\hline Harris 2017 & $\odot$ & ๑ & - & ๑ & $\odot$ & $\odot$ \\
\hline Harris 2018 & $\odot$ & ๑ & $\theta$ & ๑) & $\oplus$ & 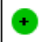 \\
\hline Ismail 2019 & $\odot$ & () & 임 & ๑) & • & 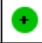 \\
\hline Mackey 2019 & $\odot$ & $?$ & - & ๑ & 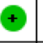 & $\odot$ \\
\hline Mann 2016 & $\odot$ & $?$ & - & ๑ & $?$ & $\odot$ \\
\hline Mansi 2015 & $\theta$ & ๑ & - & ๑) & ๑ & (†) \\
\hline Martin 2015 & $?$ & ? & • & ๑) & ๑ & $\oplus$ \\
\hline Morgan 2013 & $\odot$ & $\odot$ & - & $\odot$ & $\odot$ & $\odot$ \\
\hline Mutrie 2012 & $?$ & $?$ & - & ๑ & ๑ & + \\
\hline Nanda 2019 & - & $?$ & - & ๑) & • & + \\
\hline Oliveira 2018 & $\odot$ & ๑) & - & ๑) & $\oplus$ & + \\
\hline Poirier 2016 & $?$ & $?$ & - & ๑) & $?$ & + \\
\hline Recio-Rodriguez z 2016 & $\odot$ & $?$ & - & ๑ & ๑ & $?$ \\
\hline Renaud 2020 & ๑ & ๑ & - & ๑) & 3 & + \\
\hline Ribeiro 2014 & 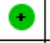 & - & అ & • & 인 & 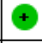 \\
\hline Tudor-Locke 2020 & $\odot$ & ? & - & $\oplus$ & $\oplus$ & $\odot$ \\
\hline Unick 2017 & ๑ & ๑ & • & ๑) & ๑ & $?$ \\
\hline Whke 2019 & - & - & అ & 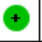 & $?$ & 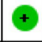 \\
\hline Yates 2009 & $\odot$ & $\oplus$ & - & $\oplus$ & $\oplus$ & 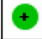 \\
\hline Yates 2017 & $\odot$ & $?$ & అ & ๑ & 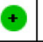 & $\odot$ \\
\hline
\end{tabular}

\section{B) End-Point Only Outcome Studies}

\begin{tabular}{|c|c|c|c|c|c|c|}
\hline & 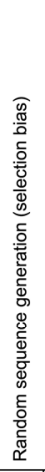 & 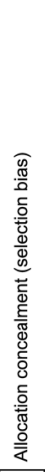 & 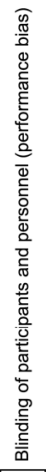 & 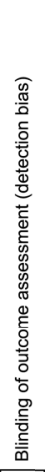 & 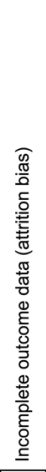 & 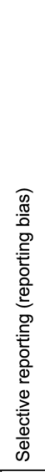 \\
\hline Ashe 2015 & + & + & $\theta$ & + & + & + \\
\hline Baker 2011 & $?$ & + & $\theta$ & + & $?$ & $\theta$ \\
\hline Cheung 2012 & $?$ & $?$ & $\theta$ & + & $?$ & $?$ \\
\hline Compernolle 2015 & + & $?$ & $\theta$ & + & $\theta$ & $?$ \\
\hline Croteau 2004 & + & $?$ & $\theta$ & + & + & $\theta$ \\
\hline Croteau 2007 & $?$ & $?$ & - & + & + & $\theta$ \\
\hline Hardeman 2020 & + & + & $\theta$ & + & + & + \\
\hline Katzmarzyk 2011 & $\odot$ & $?$ & 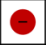 & + & + & + \\
\hline Koizumi 2009 & $?$ & $?$ & $\theta$ & + & $?$ & $\theta$ \\
\hline Lara 2016 & + & $?$ & $\theta$ & + & + & + \\
\hline Lyons 2017 & $?$ & + & $\theta$ & + & + & + \\
\hline Malik 2015 & - & $?$ & - & + & + & $?$ \\
\hline Miragall 2017 & $?$ & $?$ & ○ & + & + & $\theta$ \\
\hline Nishiguchi 2015 & + & $?$ & ○ & $?$ & + & + \\
\hline Ornes 2006 & $?$ & $?$ & ○ & + & + & $\theta$ \\
\hline Pal 2011 & $?$ & $?$ & $\theta$ & + & + & + \\
\hline Pears 2016 & $\odot$ & + & $\theta$ & + & $\theta$ & + \\
\hline Rowley 2017 & $?$ & $?$ & 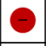 & $\odot$ & $\theta$ & $?$ \\
\hline Simons 2018 & + & $?$ & $\theta$ & + & $?$ & $\odot$ \\
\hline Suboc 2014 & $\theta$ & $?$ & $\theta$ & + & $?$ & $\odot$ \\
\hline Takahashi 2016 & + & + & $\theta$ & + & $?$ & + \\
\hline Talbot 2011 & $?$ & $?$ & $\theta$ & + & $\theta$ & $\theta$ \\
\hline Thorndike 2014 & + & $?$ & $\theta$ & $?$ & + & + \\
\hline Warren 2014 & + & + & $\theta$ & + & $?$ & + \\
\hline Yamada 2012 & $?$ & + & $\theta$ & + & + & $\theta$ \\
\hline
\end{tabular}

Fig. 2 Risk of Bias Decisions for Change-on-Change and End-Point Only Outcome Studies. a Change-on-Change Outcome Studies. b End-Point Only Outcome Studies 


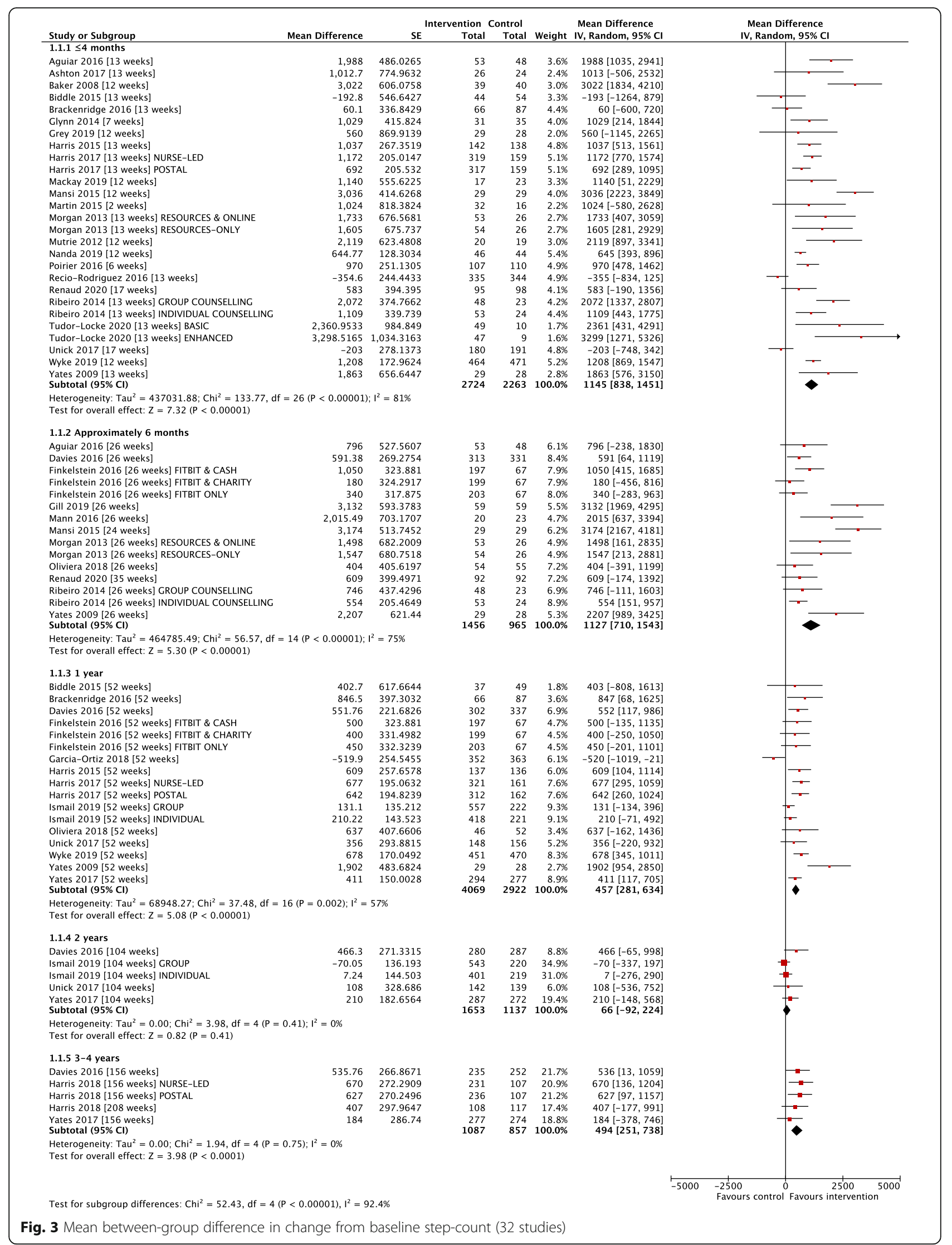


Therefore, 70 studies were included as part of this systematic review, of which:

- 32 studies provided data on mean between-group difference in change from baseline step-count ("change-on-change studies") [10-12, 24-52];

- 25 studies only provided data on mean betweengroup difference in end-point step-count ("end-point only studies") [53-77];

- 13 further studies did not provide data suitable for inclusion in our meta-analyses and were included as part of the narrative synthesis [78-90].

\section{Study characteristics}

Full details of the 57 studies included in the metaanalyses and their study characteristics are shown in Additional file 5 [10-12, 24-77]. The remaining 13 studies are described later (see 'narrative only studies' for details) [78-90].

Of the 57 RCTs included in the meta-analyses, 54 RCTs had a parallel design [10-12, 24-41, 43-57, 5972, 74-77]; 3 were cross-over studies [42, 58, 73]. Seventeen studies were conducted in the USA, 16 in the UK, 6 in Australia, 3 in Canada, Japan and Spain, 2 in Belgium, one each in Brazil, Hong Kong, Ireland, Netherlands, New Zealand, Singapore, and one was European-wide. One study identified with relevant step-count outcome data was a published abstract [64], with further details about the study highlighted in a separate paper [91]. The 57 RCTs included 16,355 participants with reported ages between 18 and 95 years, recruited from communitybased, primary care settings, or from their workplace. The majority of participants in the studies providing ethnicity information were of white ethnicity. Participants were ambulatory with the ability to participate in stepcount monitoring interventions. Most did not have specific risk factors, but included those at risk of developing Type 2 Diabetes Mellitus (T2DM), overweight with a body mass index (BMI) of $\geq 25 \mathrm{~kg} / \mathrm{m}^{2}$, and those not meeting PA recommended guidelines. Thirty-nine [10$12,24,26,33-39,41,42,44,48-50,52,54-60,62,64-$ $70,72-74,76,77]$ of the 57 RCTs used pedometers; the remaining $18[25,27-32,40,43,45-47,51,53,61,63$, $71,75]$ used other step-count monitoring interventions such as other body-worn trackers and smartphone applications. The intensity of interventions ranged from the provision of a pedometer or other step-count monitor, often with PA electronic/print resources, written exercise programmes or on-line PA updates, to those that additionally provided individual PA consultations, group counselling or financial incentives [10-12, 24-77]. The control groups received usual care or electronic / print resources and educational sessions, but without the use of a step-count monitoring device. Thirty-two RCTs provided change-on-change step-count measures, 25 RCTs provided end-point only step-count measures. The length of follow-ups ranged from 1 week to 4 years.

\section{Risk of bias within studies}

The risk of bias analysis is shown in Fig. 2. Generally, the trials were reasonably well designed and conducted to have a low risk of bias, particularly those reporting change-on-change scores. This is despite the unavoidable risks associated with trials of behavioural interventions, which cannot be blinded and so all studies were judged to have a high risk of performance bias. Outcome assessment risk of bias (detection bias) was however generally rated as low, due to the objective outcome measures involved.

\section{Effects of interventions Change-on-change studies}

As planned, our primary analysis of variation in intervention effect during follow-up is based on the 32 change-on-change studies. Fig. 3 presents a forest plot of the individual and pooled effect estimates for the 32 studies, stratified by time of follow-up. At $\leq 4$ months the pooled estimate of change indicated individuals in the intervention group were doing significantly more steps/ day than controls: Mean difference (MD) + 1145 steps/ day [95\%CI: 838 to $1451 ; 23$ studies; $\mathrm{I}^{2}=81 \%$ ]. A difference favouring the intervention group was maintained at 6 months MD + 1127 steps/day [95\%CI: 710, 1543; 11 studies; $\left.\mathrm{I}^{2}=75 \%\right]$. At 12 months the $\mathrm{MD}$ was +457 steps/day [95\%CI: 281, 634; 13 studies; $\mathrm{I}^{2}=57 \%$ ], at 2 years MD + 66 steps/day [95\% CI: - 92, 224; 4 studies; $\left.\mathrm{I}^{2}=0 \%\right]$ and at $3-4$ years $\mathrm{MD}+494$ steps/day [95\%CI: 251, 738; 3 studies; $\left.\mathrm{I}^{2}=0 \%\right]$.

The multivariate results are very comparable to the univariate estimates (Table 1), at the shorter time periods (at $\leq 4$ months $\mathrm{MD}+1126$ [CI: 787, 1466] and at approximately 6 months MD $+1050[602,1498])$. The 1year (MD + 464 [301, 626]) and 3-4 year estimates (MD $+434[191,676])$ remain statistically significant in favour of the intervention group; however, the 2-year estimate (MD + $121[-64,306])$ based on four studies, one of which has a large weighting, is not statistically significant in favour of the intervention group.

\section{End-point only studies}

Figure 4 demonstrates the pooled effect estimates for the 25 end-point only studies at all reported timepoints. At $\leq 4$ months, the mean steps/day of the intervention group was significantly greater than control group: $\mathrm{MD}+1854$ steps/day [95\% CI: 1217, 2492; 23 studies; $\left.\mathrm{I}^{2}=85 \%\right]$. This was maintained at approximately 6 months with an MD +885 steps/day [95\% CI: $-354,2125 ; 4$ studies; $\left.\mathrm{I}^{2}=70 \%\right]$, albeit without 
Table 1 Analysis of Change-on-Change Studies at different Time-points: comparison of univariate analyses at each time-point with a multivariate analysis allowing for correlation of outcomes at different time-points

\begin{tabular}{lll}
\hline Follow-up Period & $\begin{array}{l}\text { Separate Meta-analysis at Time-point } \\
\text { Mean Difference [95\% Cl] }\end{array}$ & $\begin{array}{l}\text { Multivariate Meta-analysis across Time-points } \\
\text { Mean Difference [95\% Cl] }\end{array}$ \\
\hline$\leq 4$ months & $1172[815,1528]$ & $1126[787,1466]$ \\
Approximately 6 months & $1156[672,1641]$ & $1050[602,1498]$ \\
1 year & $458[277,638]$ & $464[301,626]$ \\
2 years & $66[-92,224]$ & $121[-64,306]$ \\
$3-4$ years & $494[251,738]$ & $434[191,676]$ \\
\hline
\end{tabular}

Both Univariate and Multivariate models fitted using REML as MM option not available for multivariate model

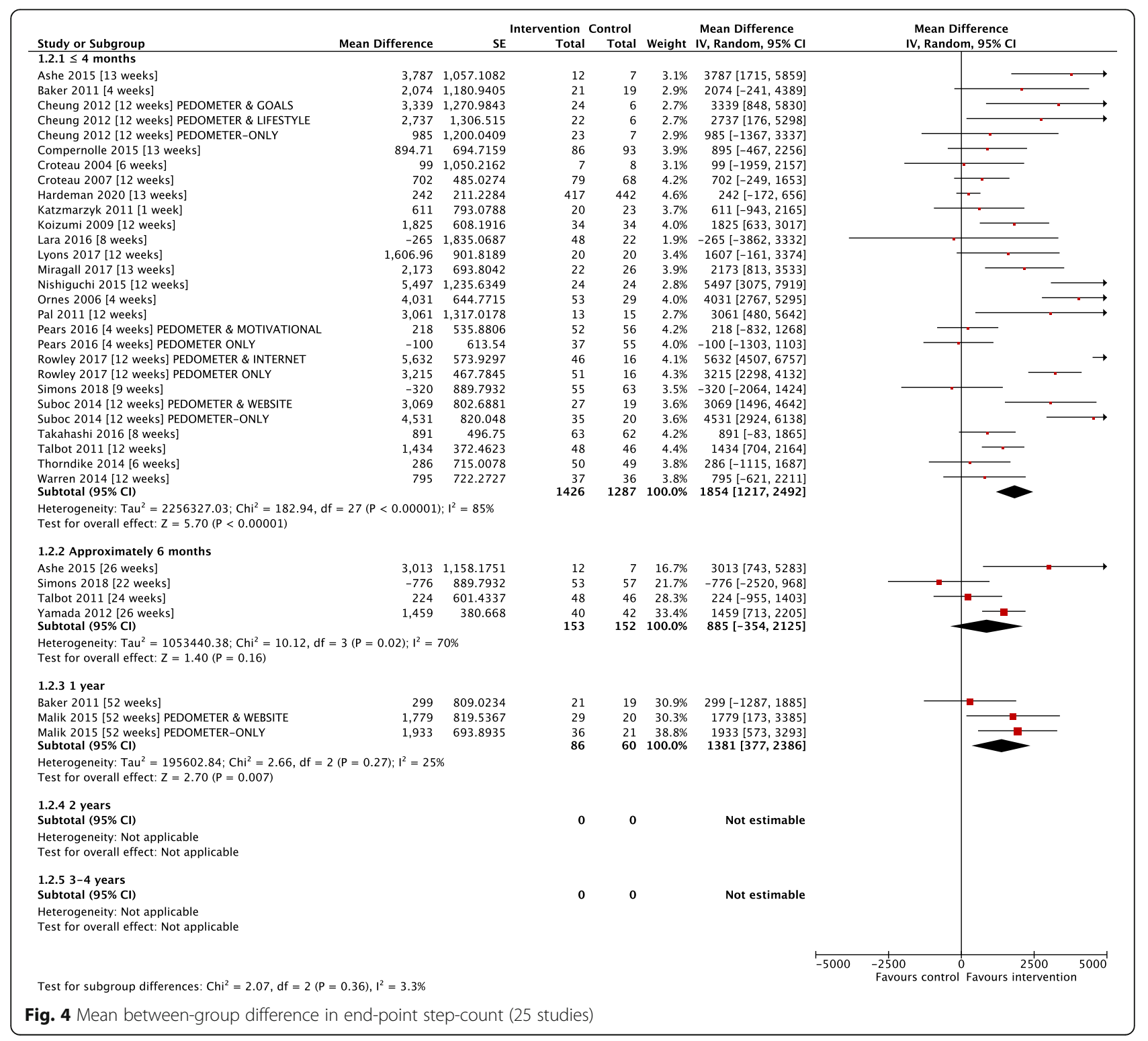


reaching levels of significance, and at 12 months with a MD 1381 steps/day [95\% CI: 377, 2386; 2 studies; $\left.\mathrm{I}^{2}=25 \%\right]$. No follow-up data were available for endpoint only studies beyond 1 year.

\section{Analysis of outcomes at $\leq 4$ months based on all study} outcome type (change-on-change and end-point only studies) Figure 5 shows the funnel plot of change-on-change studies and end-point only studies at $\leq 4$ months and demonstrates slight asymmetry.

Given the clear effect of time of follow-up on effect estimates and that the majority of studies reported effects at $\leq 4$ months, we carried out meta-regression at $\leq 4$ months' time-frame only; the results are presented in Table 2. In keeping with the forest plot, end-point only studies reported bigger effect estimates than change-onchange studies, but this difference was not statistically significant: MD 616 steps [95\%CI [-92, 1324]. This effect was more than halved when mutually adjusted for 'type of monitor' and 'intensity of intervention': MD 257 [-417, 931]. Studies using other step-count monitoring interventions (such as body-worn trackers and smartphone applications) reported lower treatment effects than those using pedometer-based interventions reported larger; MD - 927 steps [-1633, - 190]; the effect was little affected by mutual adjustment for 'study outcome type' and 'intensity of intervention' (MD - 834 steps [-1542, - 126]. Finally, studies which we rated as having higher intensity interventions (for example, those including additional PA individual or group counselling or financial incentives) had lower average effect estimates than those studies not using counselling or offering other incentives: MD -931 [-1623, -239], and this was slightly reduced by mutual adjustment for 'study outcome type' and 'type of monitor': MD -812 [-1503, -122]. A sensitivity analysis excluded 2 studies where the intervention was a smartphone only, with no body worn tracker $[32,46]$; this made minimal difference to the estimate for other (body worn) step-count monitoring interventions, which still remained significantly lower than for pedometers.

\section{Narrative only studies}

Thirteen studies were included in our systematic review, but were not included as part of the meta-analysis. Three studies provided insufficient overall intervention or control group data, and instead provided only subgroup analyses [78-80]; two of these studies concluded in favour of utilising step-count monitoring interventions to increase overall PA [78, 79], however the third study concluded that there was no evidence of efficacy [80]. A further multi-intervention arm study which provided data in the form of relative change scores also highlighted the use of a pedometer as a sufficient tool to increase steps [81]. Four studies were cross-over studies and did not provide data at the end of the first period [82-85]; there were inconsistent findings with studies reporting significant favourability towards utilising stepcount monitoring interventions [82-84], and some reporting no significant differences between intervention

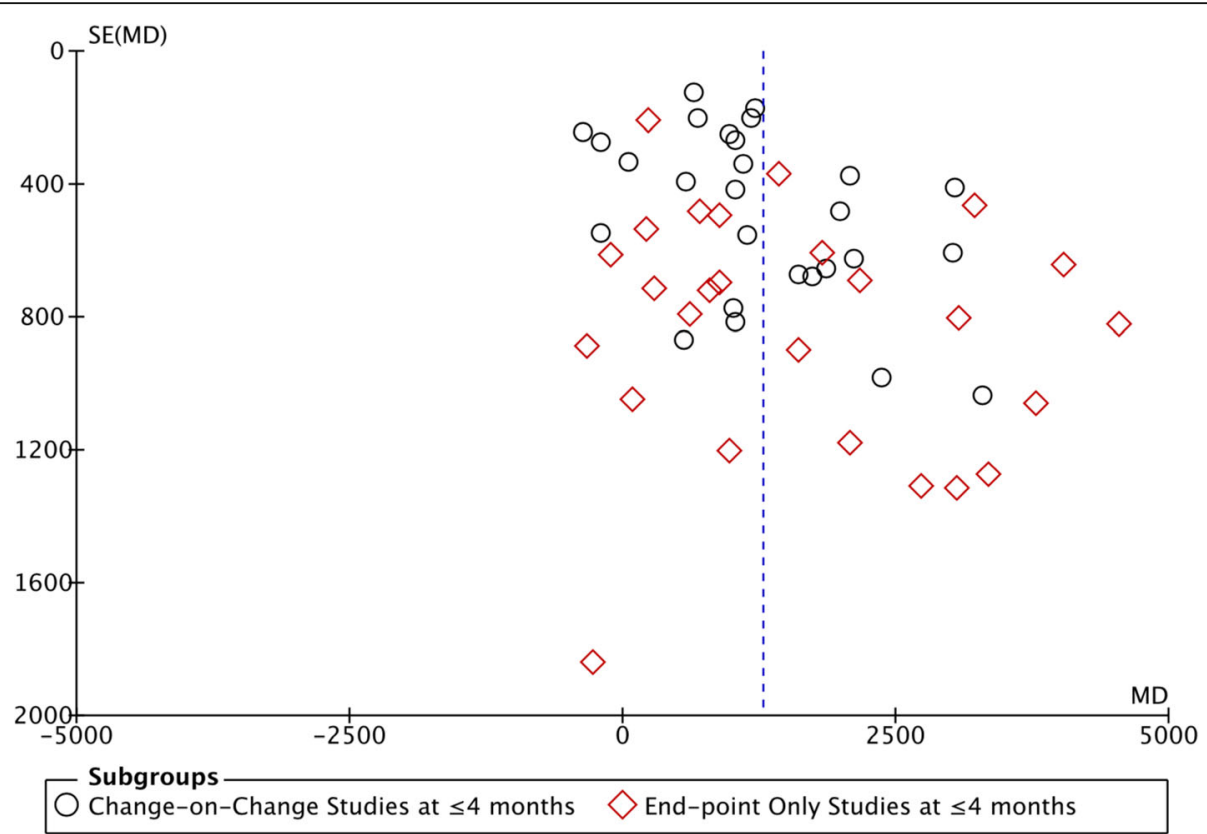

Fig. 5 Funnel Plot of Studies reporting Mean-differences of Change-on-Change Study Outcome and End-point Only Study Outcome at $\leq 4$ months Time-point 
Table 2 Univariate Meta-regression Analysis at First Time Point ( $\leq 4$ months) to Investigate Effect-Modifiers

\begin{tabular}{|c|c|c|c|c|}
\hline Effect Modifier & Factor & $\begin{array}{l}\text { Univariate Mean } \\
\text { Difference }[95 \% \mathrm{Cl}]\end{array}$ & $\begin{array}{l}\text { Univariate Difference } \\
\text { between Effect } \\
\text { Modifier Groups } \\
\text { Mean }[95 \% \mathrm{Cl}]\end{array}$ & $\begin{array}{l}\text { Mutually Adjusted Difference } \\
\text { between Effect Modifier Groups } \\
\text { Mean }[95 \% \mathrm{Cl}]\end{array}$ \\
\hline \multirow[t]{2}{*}{ Study Outcome Type } & Change-on-Change Studies & $1215[737,1692]$ & & \\
\hline & End-point Only Studies & $1831[1307,2355]$ & $616[-92,1324]$ & $257[-417,931]$ \\
\hline \multirow[t]{2}{*}{ Type of Monitor } & Pedometer & $1716[1303,2129]$ & & \\
\hline & $\begin{array}{l}\text { Other Step-count Monitoring } \\
\text { Interventions }\end{array}$ & $789[178,1401]$ & $-927[-1633,-190]$ & $-834[-1542,-126]$ \\
\hline \multirow[t]{2}{*}{ Intensity of Intervention ${ }^{a}$} & $\begin{array}{l}\text { Intervention without PA } \\
\text { individual or group counselling }\end{array}$ & $2067[1520,2614]$ & & \\
\hline & $\begin{array}{l}\text { Intervention with PA individual } \\
\text { or group counselling or other } \\
\text { incentives (e.g. cash or charity) }\end{array}$ & $1136[711,1561]$ & $-931[-1623,-239]$ & $-812[-1503,-122]$ \\
\hline
\end{tabular}

a studies had missing grade

Above all based on REML models. Using $\mathrm{mm} 2$ model has little impact on meta-regression

and control groups [85]. The remaining five studies presented data graphically using either scatter graphs or bar charts, and all provided evidence to suggest that the intervention group incorporating step-count monitoring devices significantly increased the step-count at different follow-up periods [86-90], consistent with the findings from the meta-analyses.

\section{Discussion}

\section{Principal findings}

The use of community pedometer-based or other stepcount monitoring interventions compared to usual care is associated with a significant increase in step-count when assessed using both change from baseline scores and endpoint only scores. The greatest difference in steps is seen at the shortest follow-up period at $\leq 4$ months, with intervention participants in change-on-change studies walking on average 1126 more steps/day. This significant improvement in step-count remains at approximately 6 months and 1 year with step-count monitoring interventions providing 1050 and 464 additional steps/day respectively. This overall improvement in steps is maintained at longer-term follow-up periods with differences of 121 steps/day at 2 years without reaching levels of significance and 434 steps/day at 3-4 years. Studies that presented outcome data using end-point only step-counts broadly supported these findings from change-on-change studies, but provided no data beyond 1 year. Our meta-regression analyses strongly suggest that newer devices such as bodyworn trackers and smartphone applications are less advantageous than simpler pedometers, while interventions including individual or group counselling, or financial incentives, also offered no additional step-count benefit compared to those interventions without. Taken together these findings suggest that simple pedometer-based interventions can lead to both short and long-term PA increases and should be considered more widely for public health PA promotion.

\section{Study strengths and weaknesses}

There are several strengths to this systematic review and meta-analysis. We followed PRISMA guidance and prospectively published our protocol. We were able to incorporate recent larger trials that had not been previously included in systematic reviews. Our review incorporated data from over 16,000 participants from 70 eligible studies (57 studies included in meta-analyses) to provide robust conclusions about the effect of stepcount monitoring interventions. We also incorporated different methods of measuring our primary outcome, using both change from baseline and end-point only daily step-count measurements, allowing us to combine more studies and to further strengthen our conclusions. Given that the vast majority of studies had an intervention period of approximately 3 months, and the availability of data at 1 year and beyond, our analyses provide clear evidence of maintenance of an effect many months after the intervention has finished. The risk of bias assessment demonstrated that most studies, particularly those reporting change-on-change scores, used appropriate methods to minimise bias, despite the challenges with blinding such interventions. An updated search carried out in April 2020, ensures that this review captures the most recent data relevant for this systematic review. To our knowledge, this is the first review to directly compare the effectiveness of body worn devices and smartphone applications with traditional pedometers in general population samples.

There are also limitations to consider. Since all studies had unblinded participants, the risk of performance bias was judged high, although this is a universal issue with such interventions. Moreover, we were confident that 
due to the objective outcome measures the risk of detection bias was low. Further evidence to support this comes from trials that have increased step-counts in the long term and have also reduced important clinical outcomes such as fractures and cardiovascular events [92]. Many studies did not mention the theoretical underpinning underlying their behavioural change interventions, and as such we felt that it would be difficult to compare the effect of different studies on this basis. We also explored the potential of publication bias using a funnel plot; the slight asymmetry, particularly amongst the endpoint only studies, indicated that smaller, shorter trials with positive results may have been preferentially published. We feel however, that this would have had only a small impact on our overall findings and it confirmed our preference for change-on-change step-count data as our main analysis. We recognize that there was a high degree of statistical heterogeneity, especially at the short follow-up periods, probably due to the considerably varied nature of the study designs and different intervention types.

At the 2-year time-point, the estimated treatment effect is not statistically significant; this is mainly due to the Ismail et al study, which has a weighting of $65.9 \%$ within this follow-up period [36]. This study was not effective at increasing step-counts at either the 1 year or 2-year follow-up points, for which the authors offer several explanations [36]. There was a lack of engagement with the intervention with a delay between randomisation and intervention commencement [36]. Of participants randomised to the two interventions, $28 \%$ did not start the intervention, while an additional $17 \%$ did not complete it [36]. Loss to follow-up at 24 months was also significantly higher in the intervention groups than the usual care group [36]. The authors speculated that study fatigue might explain this lack of engagement; interventions involved 10 sessions as well as considerable data collection at baseline 12 and 24 months [36]. This analysis of an unsuccessful complex intervention further strengthens our key conclusion that simple step-count monitoring interventions need to be prioritised.

An important limitation of all meta-regressions is that they are essentially observational comparisons of different trials and lack the formal rigour of within trial randomised comparisons. In the future, trials may compare different types of interventions by randomising within trial; any such trials will be better informed by the between trial comparisons we have presented. Unfortunately, many studies provided incomplete information about some aspects of the interventions such as the number and lengths of contacts, so this could not be formally analysed. Our analysis of intensity of intervention only included whether individual or group counselling or other incentives were offered, not the number nor length of contacts. We did not seek to obtain individual participant data and so were unable to explore other potential within trial effect modifiers, especially those related to demographic variables such as age, gender and socio-economic status. Finally, the studies were mostly conducted in high income countries and recruited participants of white ethnicity, so the results may not be as applicable to other countries and other ethnic groups.

\section{Comparison with other studies}

Two previous systematic reviews focussed solely on pedometer-based interventions [8,9]. Kang et al combined observational and randomised studies in both adults and children and reported a short-term increase of approximately 2000 steps/day [8]. Bravata et al demonstrated an improvement of 2491 steps/day in RCTs in adults; however, the trials included were small (maximum of 51 subjects randomised) and half were based on subjects with serious chronic diseases, which may not be generalizable [9]. Apart from inclusion of observational studies and a focus on specific diseases, other reasons that their estimates of effect were greater than our own, may include self-reported PA measures in some of their trials and small sample sizes $[8,9]$. Our more conservative estimate of change in step-counts is potentially less biased, due to inclusion of larger RCTs, with longer follow-up periods and only using objectively measured outcomes. Other reviews included pedometer-based and other broader physical activity interventions (though not body-worn trackers or smartphone applications) with both objective and selfreported PA measures [93-95]. Hobbs et al found no relationship between intervention effectiveness and the number of intervention contacts or mode of delivery and found only limited PA data beyond 12 months [95]. Our review therefore builds on previous work on step-count monitors, by focusing solely on objective physical activity measures in the adult general population, and including a number of recently published larger trials with longer follow-up periods [10-12] and trials of body-worn fitness trackers [25, 27-29, 40, 43, 45, 47, 51, 53, 61, 63, 71, 75] or smartphone only applications [30-32, 46] or combined $[25,28,40,47,53,63,71]$.

A very recent meta-analysis focussing on pedometerbased and accelerometer-based PA interventions amongst adults with cardio-metabolic conditions demonstrated small to medium PA level improvements [96]. Although this review had few long-term follow-up trials, it highlighted that pedometer-based interventions had improved association with $\mathrm{PA}$ as compared to accelerometer-based interventions [96], which is consistent with our findings comparing pedometer 
interventions with other body-worn monitors and smartphone applications. However, it demonstrated that the greatest increases in PA levels was achieved by more complex interventions, with regular contact with healthcare professionals, which differs from our own metaregression analysis [96]. This may in part be due to our different definitions of complexity as well as to the different study populations; their study focused on adults with cardio-metabolic conditions, whilst ours focussed on the general population. It is worth emphasising that only 2 studies were included in both reviews [12, 60]. A further recent review of consumer-based wearable activity trackers (not pedometers), also demonstrated increases in steps of 500-600/day compared to controls, but did not provide any comparison with pedometer interventions and lacked long term data [97].

\section{Implications for public health research, practice and policy}

From a research perspective, our review highlights two problems of inconsistent outcome reporting amongst RCTs. Some studies provided only graphical presentation of step-count results, which prevented their inclusion in meta-analyses. We were also unable to analyse the importance of both number and length of intervention sessions, due to reporting inconsistencies, which others have also highlighted [96]. Moving forward, therefore, when interventions are being investigated, it is important for study reports to provide clear information about the exact nature of the intervention, the number and length of contacts included within it and the reporting of outcomes, to provide further robust evidence to inform policy.

This review demonstrated that step-count monitoring interventions can lead to sustained increases in people's walking, but that fitness trackers and smartphone application offered no clear advantage over simpler pedometer-based interventions. It is important to consider why this might be. Step-count monitoring interventions which have been shown to be particularly effective in long-term PA change, encompass behavioural change techniques, including goal setting, selfmonitoring and feedback [98]. Pedometers can effectively provide this simple self-monitoring information with an easily understandable output [5, 98]. Fitness trackers also incorporate distance walked, elevation, the physical activity intensity, heart rate, rewards and social participation, amongst other features and have potentially been shown to be superior to pedometers [98]. However, when focussing on walking and increasing step-counts, small and simple goals may be more effective for long-term engagement of larger goals [98]. The '3,000 steps in 30 minutes' is becoming an everincreasing public health initiative [6], which is easily accomplished using a pedometer; more complex information is not required and may in fact detract from the simple message. In addition, provision of additional individual or group counselling or financial incentives also did not provide further benefit over simple step-count monitoring interventions, suggesting that a 'less is more' approach might be more suitable for walking interventions in community-based populations. This also has cost-effectiveness advantages [99], with positive implications for those commissioning PA interventions and services.

From a public health policy and practice perspective what does a long-term improvement of 434 steps per day at 3-4 years mean? Clear dose-response associations have been reported between increases in step-counts and reduced mortality, with 1000 extra steps/day being associated with a $15 \%$ lower risk in older men [100] and a $6 \%$ reduction in younger cohorts of men and women [101]. A recent meta-analysis also showed a clear doseresponse association between accelerometer measured PA and all-cause mortality, with clear evidence that the strongest benefits were seen at lower PA levels, for all activity intensities [102]. Therefore, there is evidence to suggest that any form of activity, either moderate or lighter levels are still associated with improved mortality benefit [102-104], and this is reflected within recent PA guidance [4]. This has been further corroborated by a recent large population-based cohort study, which has highlighted that engaging in leisure time aerobic activity and meeting national PA guidelines reduces all-cause and cause-specific mortality [105]. Observational studies such as those above [100-105] are problematic however, in terms of potential reverse causality; so findings from two recent pedometer-based RCTs that demonstrated significant effects on clinical outcomes, with reductions in both cardiovascular events and fractures for an approximate increase of 400-600 steps per day 3-4 years post-intervention, provide reassuring support for these findings [92].

\section{Conclusions}

Physical inactivity is an important public health concern and our findings strengthen the evidence that step-count monitoring interventions can improve longterm PA levels in adults. There was no clear advantage of newer body-worn trackers or smartphone applications over simple pedometers, and no evidence that additional individual or group counselling improved outcomes. These findings have important implications for those wishing to use PA interventions to address the public health inactivity challenge and suggest that simple pedometer-based walking interventions should be prioritised. 


\section{Supplementary information}

Supplementary information accompanies this paper at https://doi.org/10. 1186/s12966-020-01020-8.

\section{Additional file 1. MEDLINE Search Strategy.}

Additional file 2. Outline of Search Strategy for Electronic Databases.

Additional file 3. Study inclusion and exclusion criteria using the PICOS tool.

Additional file 4. Title/Abstract Screening Reviewer Checklist Eligibility.

Additional file 5. Summary of Change-on-Change Studies (32 Studies) and End-point Only Studies (25 Studies) Characteristics.

Additional file 6. Stata procedure Mvmeta.

\section{Abbreviations}

Cl: Confidence Intervals; CW: Charlotte Wahlich; DC: Derek G Cook; MD: Mean difference; MVPA: Moderate-to-vigorous physical activity; PA: Physical activity; RCT: Randomised controlled trials; RF: Rebecca Fortescue; RK: Rachel Knightly; TH: Tess Harris; UC: Umar Chaudhry

\section{Acknowledgements}

Our special thanks to Professor lan White for advice on using Stata procedure mvmeta.

\section{Authors' contributions}

UC, CW, RF, DC and TH contributed to the conception of the work, and RK assisted with the search strategy and data extraction. UC, RF and DC were responsible for the data analyses. All authors drafted the work revising it critically for important intellectual content and approved the final version to be published.

\section{Funding}

We did not receive any funding for this work.

\section{Availability of data and materials}

All data generated or analysed during this study are included in this published article [and its supplementary information files]. There was no patient and public involvement in this study. Dissemination to study participants is not applicable. Data is shared in our supplementary material and will be on the St George's, University of London data repository (URL will be provided at time of publication).

\section{Ethics approval and consent to participate}

Not applicable.

\section{Consent for publication}

Not applicable.

\section{Competing interests}

All authors have completed the ICMJE uniform disclosure form at http:// www.icmje.org/coi_disclosure.pdf and declare grant funding from the National Institute for Health Research; no financial relationships with any organisations that might have an interest in the submitted work in the previous 3 years, no other relationships or activities that could appear to have influenced the submitted work. Professor Tess Harris and Professor Derek G Cook acknowledge conflicts of interest in terms of funding from the National Institute for Health Research for the PACE-Lift and PACE-UP trials. There are no other conflicts of interest for authors.

Received: 10 March 2020 Accepted: 7 September 2020

Published online: 09 October 2020

\section{References}

1. Global action plan on physical activity 2018-2030: more active people for a healthier world. Geneva: World Health Organization; 2018. Licence: CC BYNC-SA 3.0 IGO.

2. Greaves CJ, Sheppard KE, Abraham C, Hardeman W, Roden M, Evans PH, Schwarz P. Systematic review of reviews of intervention components associated with increased effectiveness in dietary and physical activity interventions. BMC Public Health. 2011;11(1):119.

3. Morris JN, Hardman AE. Walking to health. Sports Med. 1997;23(5):306-32.

4. UK Chief Medical Officers' Physical Activity Guidelines. In.: Department of Health and Social Care; 2019.

5. Tudor-Locke C, Bassett DR. How many steps/day are enough? Sports Med. 2004;34(1):1-8.

6. Marshall SJ, Levy SS, Tudor-Locke CE, Kolkhorst FW, Wooten KM, Ji M, Macera CA, Ainsworth BE. Translating physical activity recommendations into a pedometer-based step goal: 3000 steps in 30 minutes. Am J Prev Med. 2009;36(5):410-5.

7. Harris T, Chaudhry U, Wahlich C. How do we get adults and older adults to do more physical activity and is it worth it? Br J Cardiol. 2019;26(1):8-9.

8. Kang M, Marshall SJ, Barreira TV, Lee J-O. Effect of pedometer-based physical activity interventions: a meta-analysis. Res Q Exerc Sport. 2009;80(3): 648-55.

9. Bravata DM, Smith-Spangler C, Sundaram V, Gienger AL, Lin N, Lewis R, Stave CD, Olkin I, Sirard JR. Using pedometers to increase physical activity and improve health: a systematic review. Jama. 2007;298(19):2296-304.

10. Harris T, Kerry SM, Limb ES, Furness C, Wahlich C, Victor CR, lliffe S, Whincup $\mathrm{PH}$, Ussher M, Ekelund U. Physical activity levels in adults and older adults 3-4 years after pedometer-based walking interventions: long-term followup of participants from two randomised controlled trials in UK primary care. PLoS Med. 2018;15(3):e1002526.

11. Davies MJ, Gray LJ, Troughton J, Gray A, Tuomilehto J, Faroogi A, Khunti K Yates T. A community based primary prevention programme for type 2 diabetes integrating identification and lifestyle intervention for prevention: the Let's prevent diabetes cluster randomised controlled trial. Prev Med. 2016;84:48-56.

12. Yates T, Edwardson CL, Henson J, Gray LJ, Ashra NB, Troughton J, Khunti K. Davies MJ: walking away from type 2 diabetes: a cluster randomized controlled trial. Diabet Med. 2017;34(5):698-707.

13. Limb ES, Ahmad S, Cook DG, Kerry SM, Ekelund U, Whincup PH, Victor CR, lliffe S, Ussher M, Fox-Rushby J. Measuring change in trials of physical activity interventions: a comparison of self-report questionnaire and accelerometry within the PACE-UP trial. Int J Behav Nutr Phys Act. 2019;16(1):10.

14. Dyrstad SM, Hansen BH, Holme IM, Anderssen SA. Comparison of selfreported versus accelerometer-measured physical activity. Med Sci Sports Exerc. 2014;46(1):99-106.

15. Liberati A, Altman D, Tetzlaff J, Mulrow C, Gøtzsche P, loannidis J, Clarke M, Devereaux P, Kleijnen J, Moher D. The PRISMA statement for reporting systematic reviews and meta-analyses of studies that evaluate healthcare interventions: explanation and elaboration. BMJ. 2009;339:b2700. https:// www.bmj.com/content/339/bmj.b2700.

16. Higgins JP, Green S. Cochrane handbook for systematic reviews of interventions; 2008.

17. Thomson Reuters. EndNote X7.7.1. 2016.

18. Marshall IJ, Noel-Storr A, Kuiper J, Thomas J, Wallace BC. Machine learning for identifying randomized controlled trials: an evaluation and practitioner's guide. Res Synth Methods. 2018;9(4):602-14.

19. Ouzzani M, Hammady H, Fedorowicz Z, Elmagarmid A. Rayyan-a web and mobile app for systematic reviews. Systematic Rev. 2016;5(1):210.

20. Higgins JP, Thompson SG, Deeks JJ, Altman DG. Measuring inconsistency in meta-analyses. BMJ. 2003;327(7414):557-60.

21. Review Manager (RevMan) [Computer program]. In., Version 5.3 edn. Copenhagen: The Nordic Cochrane Centre, The Cochrane Collaboration; 2014.

22. White IR. Multivariate random-effects meta-analysis. Stata J. 2009;9(1):40-56.

23. White IR. Multivariate random-effects meta-regression: updates to mvmeta. Stata J. 2011:11(2):255-70.

24. Aguiar EJ, Morgan PJ, Collins CE, Plotnikoff RC, Young MD, Callister R. Efficacy of the type 2 diabetes prevention using lifestyle education program RCT. Am J Prev Med. 2016;50(3):353-64.

25. Ashton LM, Morgan PJ, Hutchesson MJ, Rollo ME, Collins CE. Feasibility and preliminary efficacy of the 'HEYMAN' healthy lifestyle program for young men: a pilot randomised controlled trial. 2017;"16(1):2.

26. Baker G, Gray SR, Wright A, Fitzsimons C, Nimmo M, Lowry R. Mutrie NRTYJa: the effect of a pedometer-based community walking intervention "walking for wellbeing in the west" on physical activity levels and health outcomes: a 12-week randomized controlled trial. Int J Behav Nutr Phys Act. 2008;5(1):44. https://doi.org/10.1186/1479-5868-5-44. 
27. Biddle SJ, Edwardson CL, Wilmot EG, Yates T, Gorely T, Bodicoat DH, Ashra N, Khunti K, Nimmo MA, Davies MJ. A randomised controlled trial to reduce sedentary time in young adults at risk of type 2 diabetes mellitus: project STAND (Sedentary Time ANd Diabetes). PLoS One. 2015;10(12):e0143398.

28. Brakenridge $C L$, Fjeldsoe BS, Young DC, Winkler EA, Dunstan DW, Straker LM, Healy GN. Evaluating the effectiveness of organisational-level strategies with or without an activity tracker to reduce office workers' sitting time: a cluster-randomised trial. Int J Behav Nutr Phys Act. 2016;13(1):115.

29. Finkelstein EA, H BA, Bilger M, Sahasranaman A, Sloan RA, Nang EEK, Evenson KR. Effectiveness of activity trackers with and without incentives to increase physical activity (TRIPPA): a randomised controlled trial. Lancet Diabetes Endocrinol. 2016;4(12):983-95.

30. Garcia-Ortiz L, Recio-Rodriguez Jl, Agudo-Conde C, Patino-Alonso MC, Maderuelo-Fernandez J-A, Gento IR, Puig EP, Gonzalez-Viejo N, Arietaleanizbeaskoa MS, Schmolling-Guinovart Y, Gomez-Marcos MA Rodriguez-Sanchez E. Long-term effectiveness of a smartphone app for improving healthy lifestyles in general population in primary care: randomized controlled trial (Evident II study). JMIR mHealth uHealth. 2018; 6(4):e107.

31. Gill D, Blunt W, Silva NBS, Stiller-Moldovan C, Zou G, Petrella R. The HealtheSteps ${ }^{\text {TM }}$ lifestyle prescription program to improve physical activity and modifiable risk factors for chronic disease: a pragmatic randomized controlled trial. BMC Public Health. 2019;19(1):841.

32. Glynn LG, Hayes PS, Casey M, Glynn F, Alvarez-Iglesias A, Newell J, OL G, Heaney D, O'Donnell M, Murphy AW. Effectiveness of a smartphone application to promote physical activity in primary care: the SMART MOVE randomised controlled trial. Br J Gen Pract. 2014;64(624):e384-91.

33. Grey EB, Thompson D, Gillison FB. Effects of a web-based, evolutionary mismatch-framed intervention targeting physical activity and diet: a randomised controlled trial. Int J Behav Med. 2019;26(6):645-57.

34. Harris T, Kerry SM, Victor CR, Ekelund U, Woodcock A, lliffe S, Whincup PH, Beighton C, Ussher M, Limb ES, et al. A primary care nurse-delivered walking intervention in older adults: PACE (pedometer accelerometer consultation evaluation)-Lift cluster randomised controlled trial. PLoS Med. 2015;12(2):e1001783.

35. Harris T, Kerry SM, Limb ES, Victor CR, lliffe S, Ussher M, Whincup PH, Ekelund U, Fox-Rushby J, Furness C, et al. Effect of a Primary Care Walking Intervention with and without Nurse Support on Physical Activity Levels in 45- to 75-Year-Olds: the Pedometer And Consultation Evaluation (PACE-UP) Cluster Randomised Clinical Trial. PLoS Med. 2017;14(1):e1002210.

36. Ismail K, Stahl D, Bayley A, Twist K, Stewart K, Ridge K, Britneff E, Ashworth M, de Zoysa N, Rundle J. Enhanced motivational interviewing for reducing weight and increasing physical activity in adults with high cardiovascular risk: the MOVE IT three-arm RCT. Health Technol Assess (Winchester, England). 2019;23(69):1.

37. Mackey DC, Perkins AD, Tai KH, Sims-Gould J, McKay HA. Men on the move: a randomized controlled feasibility trial of a scalable, choice-based, physical activity and active transportation intervention for older men. J Aging Phys Act. 2019;27(4):489-502.

38. Mann DM, Palmisano J, Lin JJ. A pilot randomized trial of technologyassisted goal setting to improve physical activity among primary care patients with prediabetes. Prev Med Rep. 2016;4:107-12.

39. Mansi S, Milosavljevic S, Tumilty S, Hendrick P, Higgs C, Baxter DG. Investigating the effect of a 3-month workplace-based pedometer-driven walking programme on health-related quality of life in meat processing workers: a feasibility study within a randomized controlled trial. 2015:"15(1): $1-2$.

40. Martin SS, Feldman DI, Blumenthal RS, Jones SR, Post WS, McKibben RA, Michos ED, Ndumele CE, Ratchford EV, Coresh J, et al. mActive: a randomized clinical trial of an automated mHealth intervention for physical activity promotion. J Am Heart Assoc. 2015;4(11):e002239.

41. Morgan P, Callister R, Collins C, Plotnikoff R, Young M, Berry N, McElduff P, Burrows T, Aguiar E, Saunders K. The SHED-IT community trial: a randomised controlled trial of internet- and paper-based weight loss programs tailored for overweight and obese men. Obes Res Clin Pract. 2012;6:30-1.

42. Mutrie N, Doolin O, Fitzsimons CF, Grant PM, Granat M, Grealy M, Macdonald H, MacMillan F, McConnachie A, Rowe DA, et al. Increasing older adults' walking through primary care: results of a pilot randomized controlled trial. Family Pract. 2012;29(6):633-42

43. Nanda S, Hurt RT, Croghan IT, Mundi MS, Gifford SL, Schroeder DR, Fischer KM, Bonnes SL. Improving physical activity and body composition in a medical workplace using brief goal setting. Mayo Clin Proc Innov Qual Outcomes. 2019;3(4):495-505.

44. Oliveira JS, Sherrington C, Paul SS, Ramsay E, Chamberlain K, Kirkham C, D O' Rourke S, Hassett L, Tiedemann A. A combined physical activity and fall prevention intervention improved mobility-related goal attainment but not physical activity in older adults: a randomised trial. J Phys. 2019:65(1):16-22.

45. Poirier J, Bennett WL, Jerome GJ, Shah NG, Lazo M, Yeh HC, Clark JM, Cobb NK. Effectiveness of an activity tracker- and internet-based adaptive walking program for adults: a randomized controlled trial. J Med Internet Res. 2016; 18(2):e34.

46. Recio-Rodriguez JI, Agudo-Conde C, Martin-Cantera C, González-Viejo MN, Fernandez-Alonso MC, Arietaleanizbeaskoa MS, Schmolling-Guinovart Y, Maderuelo-Fernandez JA, Rodriguez-Sanchez E, Gomez-Marcos MA, et al. Short-Term Effectiveness of a Mobile Phone App for Increasing Physical Activity and Adherence to the Mediterranean Diet in Primary Care: a Randomized Controlled Trial (EVIDENT II Study). J Med Internet Res. 2016; 18(12):e331.

47. Renaud LR, Jelsma JG, Huysmans MA, van Nassau F, Lakerveld J, Speklé EM, Bosmans JE, Stijnman DP, Loyen A, van der Beek AJ. Effectiveness of the multi-component dynamic work intervention to reduce sitting time in office workers-results from a pragmatic cluster randomised controlled trial. Appl Ergon. 2020;84:103027.

48. Ribeiro MA, Martins MA, Carvalho CR. Interventions to increase physical activity in middle-age women at the workplace: a randomized controlled trial. Med Sci Sports Exerc. 2014;46(5):1008-15.

49. Tudor-Locke C, Schuna JM, Swift DL, Dragg AT, Davis AB, Martin CK, Johnson WD, Church TS. Evaluation of Step-Counting Interventions Differing on Intensity Messages. J Phys Act Health. 2019;17(aop):21-8.

50. Unick JL, Lang W, Williams SE, Bond DS, Egan CM, Espeland MA, Wing RR, Tate DF, Group SR. Objectively-assessed physical activity and weight change in young adults: a randomized controlled trial. Int J Behav Nutr Phys Act. 2017;14(1):165.

51. Wyke S, Bunn C, Andersen E, Silva MN, Van Nassau F, McSkimming P, Kolovos S, Gill JM, Gray CM, Hunt K. The effect of a programme to improve men's sedentary time and physical activity: the European fans in training (EuroFIT) randomised controlled trial. PLoS Med. 2019;16(2):e1002736.

52. Yates T, Davies M, Gorely T, Bull F, Khunti K. Effectiveness of a pragmatic education program designed to promote walking activity in individuals with impaired glucose tolerance: a randomized controlled trial. Diabetes Care. 2009;32(8):1404-10.

53. Ashe MC, Winters M, Hoppmann CA, Dawes MG, Gardiner PA, Giangregorio LM, Madden KM, McAllister MM, Wong G, Puyat JH, et al. "Not just another walking program": everyday activity supports you (EASY) model-a randomized pilot study for a parallel randomized controlled trial. Pilot Feasibility Stud. 2015;1(4):1-12.

54. Baker G, Mutrie N, Lowry R. A comparison of goals set in steps using a pedometer and goals set in minutes: A randomized controlled trial. Int J Health Promotion Educ. 2011:49(2):60-8.

55. Cheung PP, Chen S, Wong EM. Using Mobile Phone Messages in Pedometer-Based Intervention for Working Adults in Hong Kong. Asian J Exerc Sports Sci. 2012;9(2).

56. Compernolle S, Vandelanotte C, Cardon G, De Bourdeaudhuij I, De Cocker K Effectiveness of a web-based, computer-tailored, pedometer-based physical activity intervention for adults: a cluster randomized controlled trial. J Med Internet Res. 2015;17(2):e38.

57. Croteau KA, Richeson NE, Vines SW, Jones DB. Effects of a pedometer-based physical activity program on older Adults' mobility-related self-efficacy and physical performance. Act Adapt Aging. 2004;28(2):19-33.

58. Croteau KA, Richeson NE, Farmer BC, Jones DB. Effect of a pedometer-based intervention on daily step counts of community-dwelling older adults. Res Q Exerc Sport. 2007;78(5):401-6.

59. Hardeman W, Mitchell J, Pears S, Van Emmenis M, Theil F, Gc VS, Vasconcelos JC, Westgate K, Brage S, Suhrcke M. Evaluation of a very brief pedometer-based physical activity intervention delivered in NHS health checks in England: the VBI randomised controlled trial. PLoS Med. 2020; 17(3):e1003046.

60. Katzmarzyk PT, Champagne CM, Tudor-Locke C, Broyles ST, Harsha D, Kennedy $\mathrm{BM}$, Johnson WD. A short-term physical activity randomized trial in the Lower Mississippi Delta. Plos One [electronic resource]. 2011;6(10):e26667.

61. Koizumi D, Rogers NL, Rogers ME, Islam MM, Kusunoki M, Takeshima N. Efficacy of an accelerometer-guided physical activity intervention in community-dwelling older women. J Phys Act Health. 2009;6(4):467-74. 
62. Lara J, O'Brien N, Godfrey A, Heaven B, Evans EH, Lloyd S, Moffatt S, Moynihan $P J$, Meyer TD, Rochester $L$, et al. Pilot randomised controlled trial of a webbased intervention to promote healthy eating, physical activity and meaningful social connections compared with usual care control in people of retirement age recruited from workplaces. PLoS One. 2016;11(7):e0159703.

63. Lyons EJ, Swartz MC, Lewis ZH, Martinez E. Jennings K. Feasibility and acceptability of a wearable technology physical activity intervention with telephone counseling for mid-aged and older adults: a randomized controlled pilot trial. JMIR mHealth uHealth. 2017;5(3):e28.

64. Malik MA, Suboc T, Strath SJ, Wang J, Tanner MJ, Ying R, Widlansky M. Impact of increasing physical activity over 12 weeks in previously sedentary older adults: A 1-year follow up. J Am Coll Cardiol. 2015;65(10):A1451.

65. Miragall M, Domínguez-Rodríguez A, Navarro J, Cebolla A, Baños RM. Increasing physical activity through an internet-based motivational intervention supported by pedometers in a sample of sedentary students: A randomised controlled trial. Psychol Health. 2018;33(4):465-82.

66. Nishiguchi S, Yamada M, Tanigawa T, Sekiyama K, Kawagoe T, Suzuki M, Yoshikawa S, Abe N, Otsuka Y, Nakai R. A 12-week physical and cognitive exercise program can improve cognitive function and neural efficiency in community-dwelling older adults: a randomized controlled trial. J Am Geriatr Soc. 2015;63(7):1355-63.

67. Ornes LL. A theory-based, Web-mediated physical activity intervention for college women. The University of Utah; 2006. p. 280.

68. Pal S, Cheng C, Ho S. The effect of two different health messages on physical activity levels and health in sedentary overweight, middle-aged women. BMC Public Health. 2011;11(1):204.

69. Pears S, Bijker M, Morton K, Vasconcelos J, Parker RA, Westgate K, Brage S,

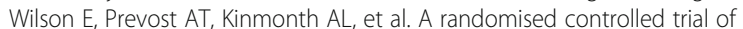
three very brief interventions for physical activity in primary care. BMC Public Health. 2016;16(1):1033.

70. Rowley TW, Lenz EK, Swartz AM, Miller NE, Maeda H, Strath SJ. Efficacy of an individually tailored, internet-mediated physical activity intervention in older adults: a randomized controlled trial. J Appl Gerontol. 2019;38(7):1011-22.

71. Simons D, De Bourdeaudhuij I, Clarys P, De Cocker K, Vandelanotte C, Deforche B. Effect and process evaluation of a smartphone app to promote an active lifestyle in lower educated working young adults: cluster randomized controlled trial. JMIR mHealth uHealth. 2018;6(8):e10003.

72. Suboc TB, Strath SJ, Dharmashankar K, Harmann L, Couillard A, Malik M, Haak K, Knabel D, Widlansky ME. The impact of moderate intensity physical activity on cardiac structure and performance in older sedentary adults. Int J Cardiol Heart Vessels. 2014;4(1):19-24.

73. Takahashi PY, Quigg SM, Croghan IT, Schroeder DR, Ebbert JO. Effect of pedometer use and goal setting on walking and functional status in overweight adults with multimorbidity: a crossover clinical trial. Clin Interv Aging. 2016:11:1099-106.

74. Talbot LA, Metter EJ, Morrell CH, Frick KD, Weinstein AA, Fleg JL. A pedometer-based intervention to improve physical activity, fitness, and coronary heart disease risk in National Guard personnel. Military Med. 2011; 176(5):592-600.

75. Thorndike AN, Mills S, Sonnenberg L, Palakshappa D, Gao T, Pau CT, Regan S. Activity monitor intervention to promote physical activity of physiciansin-training: randomized controlled trial. PLoS One. 2014;9(6):e100251.

76. Warren FC, Stych K, Thorogood M, Sharp DJ, Murphy M, Turner KM, Holt TA Searle A, Bryant S, Huxley C, et al. Evaluation of different recruitment and randomisation methods in a trial of general practitioner-led interventions to increase physical activity: a randomised controlled feasibility study with factorial design. Trials. 2014;15(1):134.

77. Yamada M, Mori S, Nishiguchi S, Kajiwara Y, Yoshimura K, Sonoda T, Nagai K, Arai H, Aoyama T. Pedometer-based behavioral change program can improve dependency in sedentary older adults: a randomized controlled trial. J Frailty Aging. 2012;1(1):39-44.

78. Eisenberg MH, Phillips L, Fowler L, Moore PJ. The impact of E-diaries and accelerometers on young adults' perceived and objectively assessed physical activity. Psychol Sport Exerc. 2017;30:55-63.

79. Kovelis D, Zabatiero J, Furlanetto KC, Mantoani LC, Proença M, Pitta F. Shortterm effects of using pedometers to increase daily physical activity in smokers: a randomized trial. Respir Care. 2012;57(7):1089-97.

80. Melton BF, Buman MP, Vogel RL, Harris BS, Bigham LE. Wearable devices to improve physical activity and sleep: a randomized controlled trial of college-aged African American women. J Black Stud. 2016;47(6):610-25.
81. Van Hoye K, Wijtzes Al, Lefevre J, De Baere S, Boen F. Year-round effects of a four-week randomized controlled trial using different types of feedback on employees' physical activity. BMC Public Health. 2018;18(1):492.

82. Marshall AL. Should all steps count when using a pedometer as a measure of physical activity in older adults? J Phys Act Health. 2007;4(3):305-14.

83. Yang YP, Wang CJ, Wang JJ, Lin CW, Yang YTC, Wang JS, Yang YK, Yang YC The Effects of an Activity Promotion System on active living in overweight subjects with metabolic abnormalities RTY - Journal articles. Obes Res Clin Pract. 2017;11(6):718-27.

84. Zabatiero J, Kovelis D, Furlanetto KC, Mantoani LC, Proenca M, Pitta F. Comparison of two strategies using pedometers to counteract physical inactivity in smokers. Nicotine Tob Res. 2014;16(5):562-8.

85. Matevey C, Rogers LQ, Dawson E, Tudor-Locke C. Lack of reactivity during pedometer self-monitoring in adults. Meas Phys Educ Exerc Sci. 2006;10(1): $1-11$.

86. Harries T, Eslambolchilar P, Rettie R, Stride C, Walton S, Van Woerden HC. Effectiveness of a smartphone app in increasing physical activity amongst male adults: a randomised controlled trial. BMC Public Health. 2016;16:925

87. Pal S, Cheng C, Egger G, Binns C, Donovan R. Using pedometers to increase physical activity in overweight and obese women: a pilot study. BMC Public Health. 2009;9(1):309.

88. Staudter M, Dramiga S, Webb L, Hernandez D, Cole R. Effectiveness of pedometer use in motivating active duty and other military healthcare beneficiaries to walk more. US Army Med Department J. 2011:108-19.

89. Strath SJ, Swartz AM, Parker SJ, Miller NE, Grimm EK, Cashin SE. A pilot randomized controlled trial evaluating motivationally matched pedometer feedback to increase physical activity behavior in older adults. J Phys Act Health. 2011:8:S267-74.

90. Walsh JC, Corbett T, Hogan M, Duggan J, McNamara A. An mHealth intervention using a smartphone app to increase walking behavior in Young adults: a pilot study. JMIR mHealth uHealth. 2016;4(3):e109.

91. Suboc TB, Strath SJ, Dharmashankar K, Coulliard A, Miller N, Wang J, Tanner MJ, Widlansky ME. Relative importance of step count, intensity, and duration on physical activity's impact on vascular structure and function in previously sedentary older adults. J Am Heart Assoc. 2014;3(1):e000702.

92. Harris T, Limb ES, Hosking F, Carey I, DeWilde S, Furness C, Wahlich C, Ahmad S, Kerry S, Whincup P. Effect of pedometer-based walking interventions on long-term health outcomes: prospective 4-year follow-up of two randomised controlled trials using routine primary care data. PLOS Med. 2019;16(6):e1002836.

93. Conn VS, Hafdahl AR, Mehr DR. Interventions to increase physical activity among healthy adults: meta-analysis of outcomes. Am J Public Health. 2011; 101(4):751-8.

94. Orrow G, Kinmonth A-L, Sanderson S, Sutton S. Effectiveness of physical activity promotion based in primary care: systematic review and metaanalysis of randomised controlled trials. BMJ. 2012;344:e1389.

95. Hobbs N, Godfrey A, Lara J, Errington L, Meyer TD, Rochester L, White M, Mathers JC, Sniehotta FF. Are behavioral interventions effective in increasing physical activity at 12 to 36 months in adults aged 55 to 70 years? A systematic review and meta-analysis. BMC Med. 2013;11(1):75.

96. Hodkinson A, Kontopantelis E, Adeniji C, van Marwijk H, McMillan B, Bower $P$, Panagioti M. Accelerometer-and pedometer-based physical activity interventions among adults with Cardiometabolic conditions: a systematic review and meta-analysis. JAMA Netw Open. 2019;2(10):e1912895.

97. Brickwood K-J, Watson G, O'Brien J, Williams AD. Consumer-based wearable activity trackers increase physical activity participation: systematic review and meta-analysis. JMIR mHealth uHealth. 2019;7(4):e11819.

98. Sullivan AN, Lachman ME. Behavior change with fitness technology in sedentary adults: a review of the evidence for increasing physical activity. Front Public Health. 2017:4:289.

99. Anokye N, Fox-Rushby J, Sanghera S, Cook DG, Limb E, Furness C, Kerry SM, Victor CR, lliffe S, Ussher M. Short-term and long-term cost-effectiveness of a pedometer-based exercise intervention in primary care: a within-trial analysis and beyond-trial modelling. BMJ Open. 2018;8(10):e021978.

100. Jefferis BJ, Parsons TJ, Sartini C, Ash S, Lennon LT, Papacosta O, Morris RW, Wannamethee SG, Lee I-M, Whincup PH. Objectively measured physical activity, sedentary behaviour and all-cause mortality in older men: does volume of activity matter more than pattern of accumulation? Br J Sports Med. 2019;53(16):1013-20. 
101. Lee I-M, Shiroma EJ, Kamada M, Bassett DR, Matthews CE, Buring JE. Association of Step Volume and Intensity With All-Cause Mortality in Older Women. JAMA Intern Med. 2019;179(8):1105-12.

102. Ekelund U, Tarp J, Steene-Johannessen J, Hansen BH, Jefferis B, Fagerland MW, Whincup P, Diaz KM, Hooker SP, Chernofsky A. Dose-response associations between accelerometry measured physical activity and sedentary time and all cause mortality: systematic review and harmonised meta-analysis. BMJ. 2019;366:14570.

103. Fishman El, Steeves JA, Zipunnikov V, Koster A, Berrigan D, Harris TA, Murphy R. Association between objectively measured physical activity and mortality in NHANES. Med Sci Sports Exerc. 2016;48(7):1303.

104. Dwyer T, Pezic A, Sun C, Cochrane J, Venn A, Srikanth V, Jones G, Shook R, Sui $X$, Ortaglia A. Objectively measured daily steps and subsequent long term all-cause mortality: the tasped prospective cohort study. PLoS One. 2015;10(11):e0141274.

105. Zhao M, Veeranki SP, Magnussen CG, Xi B. Recommended physical activity and all cause and cause specific mortality in US adults: prospective cohort study. BMJ. 2020:370. https://doi.org/10.1136/bmj.m2031.

\section{Publisher's Note}

Springer Nature remains neutral with regard to jurisdictional claims in published maps and institutional affiliations.

Ready to submit your research? Choose BMC and benefit from:

- fast, convenient online submission

- thorough peer review by experienced researchers in your field

- rapid publication on acceptance

- support for research data, including large and complex data types

- gold Open Access which fosters wider collaboration and increased citations

- maximum visibility for your research: over $100 \mathrm{M}$ website views per year

At BMC, research is always in progress.

Learn more biomedcentral.com/submissions 